\title{
The impact of benchmarking operating room efficiency within the Veterans Health Administration
}

\author{
Marilyn Lynn ${ }^{1}$, Douglas Bronson ${ }^{1}$, William Gunnar*1,2 \\ ${ }^{1}$ VHA National Surgery Office, Washington, DC, United States \\ ${ }^{2}$ The George Washington University, Washington, DC, United States
}

Received: August 15, 2018

Accepted: October 16, 2018

Online Published: October 28, 2018

DOI: $10.5430 /$ ijh.v5n1p8

URL: https://doi.org/10.5430/ijh.v5n1p8

\begin{abstract}
Purpose: The Department of Veterans Affairs (VA) provides surgical care and services through a network of Veterans Health Administration (VHA) Surgical Programs. This study examined the impact of benchmarking on improvements in VHA surgery program operating room efficiency.

Methods: The VA National Surgery Office (NSO) developed the operating room (OR) Efficiency Matrix with four common metrics that characterize OR processes. The OR Efficiency Matrix assigned a performance level to each VHA Surgery Program identified in the NSO Quarterly Report. The NSO Quarterly Report provided ongoing and regular feedback allowing VHA Surgery Programs to develop action plans and improve performance.

Results: Beginning with the Fiscal Year (FY) 2013 Quarter (Q) 2 NSO Quarterly Report, the NSO has been reporting to VHA Surgery Programs on the OR Efficiency Matrix through several tables and figures in the NSO Quarterly Report. Overall, raw metric rates have improved nationally, with most improvements coming in the metrics of OR first time starts and surgical case cancellation.

Conclusions: The NSO developed and implemented the OR Efficiency Matrix, representing four well recognized metrics, to assess, track, and report OR efficiency at 137 VHA Surgery Programs. This internal benchmarking process and data reporting was associated with sustainable improvements in OR efficiency over time.
\end{abstract}

Key Words: OR efficiency, First-time starts, Cancellation, Utilization, Lag time, Improvement, Veterans

\section{INTRODUCTION}

The Veterans Health Administration (VHA) is the largest integrated healthcare organization in the United States, providing healthcare services to over 9 million enrolled Veterans. ${ }^{[1]}$ The VHA has established 137 Surgery Programs, including 111 inpatient facilities and 26 Ambulatory Surgery Centers (ASC), that perform over 420,000 surgical procedures a year utilizing approximately 870 operating rooms (ORs). ${ }^{[2]} \mathrm{A}$ strategic goal of the VHA National Surgery Office (NSO) is to optimize OR efficiency with intent to meet Veteran demands for services, ensure Veteran and provider staff satisfaction, and provide cost effective services. Such benefits of improved OR efficiency is well recognized, ${ }^{[3]}$ however, established national benchmarks are lacking. ${ }^{[4]}$ This study evaluates the impact of aggregating four well known OR efficiency metrics into a matrix and efforts to provide stratified reporting of VHA Surgery Programs by performance over time. To be determined is whether regular and ongoing reporting of OR Efficiency data is sufficient to drive sustainable improvement across a large healthcare organization as

*Correspondence: William Gunnar; Email: William.gunnar@va.gov; Address: Veterans Health Administration, National Surgery Office (10NC2), 810 Vermont Ave, Washington, DC, 20420, United States. 
each of the VHA Surgery Programs are left to respond to results independently.

\section{Methods}

\subsection{OR metrics}

The NSO provides comprehensive VHA Surgery Programlevel quarterly reports, along with an annual report, to support regular and ongoing quality improvement of VHA surgical care. These reports provide a foundation for evaluation of the quality and outcomes of surgical care and services, and enable iterative quality improvement for each VHA Surgery Program through ongoing summaries, riskadjusted outcomes, long-term trending, and both regional and national comparisons. ${ }^{[5]}$

At the beginning of Fiscal Year 2013 (FY13), the NSO developed the OR Efficiency Matrix based on an analysis of available VHA data related to OR efficiency extracted from the Veterans Information Systems and Technology Architecture (VistA) Surgery Package. OR efficiency metrics were selected that were measurable, independent, and highly representative of OR efficiency based on a review of published studies. ${ }^{[6-9]}$ This effort resulted in four OR efficiency metrics defined as:

- On-Time First Time Starts - The rate at which the first case in an OR begins (wheels in) on or before the scheduled start time.

- Surgical Case Cancellation Rate - The rate at which cases are cancelled cases versus scheduled (the number of cancelled cases plus the number of completed cases).

- OR Utilization - The total OR run time in equipped ORs divided by the total OR staffing hours. An equipped OR meets the VHA requirements (size, cleaning, air handling, etc.) and has the equipment necessary for staff to conduct surgical procedures. The $\mathrm{OR}$ run time is computed for each OR room for an individual OR day and defined as wheels in for the first patient of the day in that room to wheels out for the last patient. Total OR run time is the sum of all individual OR day run times.

- OR Lag Time - A lag time is the time between consecutive cases (wheels out to wheels in) in an individual OR on a given day. OR lag times greater than 180 minutes are excluded with the assumption that such delays represent a break in the OR schedule. The OR Lag Time metric is the number of lag times that meet the threshold time divided by the total number of lag times.

The OR Efficiency Matrix content contained in the NSO Quarterly Report consists of summary tables and figures for Published by Sciedu Press all the metrics at each VHA Surgery Program. This tool allows the facilities to identify areas for improvement, measure success over time and identify sustainable interventions. Statistics are provided for current quarter and rolling 12 months, along with various subsets, e.g., surgical specialty, cancellation reason, and individual operating rooms, to assist facilities in identifying process improvement strategies. For example, if an OR is not running for the fully staffed day or an OR has longer lag times than the reporting thresholds, the data can be used to target specific areas for system improvements using the utilization and lag time statistics. Similarly, if the cancellation reasons for patient health spikes in a quarter, the VHA Surgery Program might investigate the preoperative process. The NSO Quarterly Report also provides regional comparators allowing a quick means of comparison between facilities so that best practices can be discussed and shared within the VHA surgical community.

\subsection{OR lag time thresholds}

Table 1 describes the OR Lag Time Thresholds. The complexity groupings and thresholds were determined by a distributional analysis of current VHA OR Lag Times. The complexity group column in Table 1 describes the types of cases preceding and following an individual lag time calculation based on the complexity of the procedure. The VHA establishes an operative complexity assignment of ambulatory, standard, intermediate and complex to all surgical procedures. ${ }^{[10,11]}$ However, the first group is not defined by complexity but rather by surgical specialty because it was determined through the distributional analysis that these two specialties had similar lag times and separated them out from the other complexity groups. Therefore, the OR Lag Time threshold for the 1st group indicates both the preceding and following cases have a surgical specialty of either ophthalmology or anesthesia pain procedure. The second group indicates operative complexity whereby the preceding and following cases must be either ambulatory or standard inpatient. In the last group one of the cases must be at either the intermediate or complex level. Continuous monitoring of OR Lag Time distribution over time allowed the NSO to modify the OR Lag Time threshold in Fiscal Year 2016 Quarter 1 (FY16-Q1) in relationship to improved performance over time.

\subsection{OR efficiency matrix scoring bins}

The four metrics are scored for the rolling 12-month rates of each VHA Surgery Program. Table 2 provides the scoring bins that were initially implemented and those used since the FY16 Q1 update to the OR Efficiency Matrix. Scoring (1 low to 4 high) thresholds were developed for each metric based on a distributional analysis. 
Table 1. OR lag time thresholds

\begin{tabular}{lll}
\hline & Complexity Group & OR Lag Time Threshold \\
\hline \multirow{3}{*}{ FY13 Q2 through FY15 Q4 } & Ophthalmology or Anesthesia Specialty & 30 minutes \\
& Ambulatory or Standard-to-Standard Complexity & 55 minutes \\
& Other Inpatient Complexity Pairings & 75 minutes \\
& Ophthalmology or Anesthesia Specialty & 20 minutes \\
FY16 Q1 through present & Ambulatory or Standard-to-Standard Complexity & 35 minutes \\
& Other Inpatient Complexity Pairings & 50 minutes \\
\hline
\end{tabular}

Table 2. OR efficiency matrix scoring bins

\begin{tabular}{llllll}
\hline & Score & First Time Starts & Case Cancellation & OR Utilization & OR Lag Time \\
\hline \multirow{2}{*}{$\begin{array}{l}\text { FY13 Q2 } \\
\text { through }\end{array}$} & 2 & $<30 \%$ & $>16 \%$ & $<40 \%$ & $<60 \%$ \\
FY15 Q4 & 3 & $30 \%$ to $<60 \%$ & $>12 \%$ to $16 \%$ & $40 \%$ to $<60 \%$ & $60 \%$ to $75 \%$ \\
& 4 & $>=80 \%$ to $<80 \%$ & $>8 \%$ to $12 \%$ & $60 \%$ to $<80 \%$ & $75 \%$ to $85 \%$ \\
& 1 & $<50 \%$ & $<=8 \%$ & $>=80 \%$ & $>=85 \%$ \\
FY16 Q1 & 2 & $50 \%$ to $<70 \%$ & $>13 \%$ & $40 \%$ to $<60 \%$ & $40 \%$ to $55 \%$ \\
through & 3 & $70 \%$ to $<85 \%$ & $>6 \%$ to $9 \%$ & $60 \%$ to $<80 \%$ & $55 \%$ to $70 \%$ \\
present & 4 & $>=85 \%$ & $<=6 \%$ & $>=80 \%$ & $>=70 \%$ \\
\hline
\end{tabular}

\subsection{OR efficiency matrix target plots}

The NSO Quarterly Report summarizes the OR Efficiency Matrix scores for each Veterans Integrated Service Network (VISN) in target plots for quick regional-level assessment of low and high performers (see Figure 1).

Several mechanisms allow monitoring and feedback for these data. In addition to the NSO Quarterly Report, NSO leadership attends annual surgery meetings for each VISN where the data are discussed and strategies for improving OR efficiency are planned. Every VISN also holds monthly conference calls to review the OR efficiency metrics and strategize improvement methods. These meetings support organizational learning through reporting of ongoing performance improvement activities at both the VISN and national level.

\subsection{Redefining or efficiency matrix}

The NSO observed improvements in OR efficiency at the VHA Surgery Programs over time resulting in the following refinements:

- Accounting for Case Cancellation - With the FY14 Q3 NSO Quarterly Report, cases cancelled more than 2 days prior to the scheduled date of surgery were excluded from the cancellation rate calculation as these changes were unlikely to impact efficiency on the day of surgery.

- Accounting for First-time Starts - Initially, a VHA Surgery Program received first time start credit only if the first scheduled case in an OR started on-time. Beginning with the FY16 Q1 NSO Quarterly Report, the surgery program received first time start credit if any case started on or before the first scheduled start time. This modification gave facilities credit for adjusting to day-of-surgery changes.

- OR Lag Time threshold changes - With the FY16 Q1 NSO Quarterly Report, the OR Lag Time thresholds were advanced in relationship to improvements by VHA Surgery Programs in meeting this metric (see Table 1).

- OR Efficiency Matrix scoring bin changes - With the FY16 Q1 NSO Quarterly Report, the OR efficiency thresholds were advanced in relationship to improvements by VHA Surgery Programs in meeting this metric (see Table 2).

\section{RESUltS}

Beginning with the FY13 Q2 NSO Quarterly Report, the OR Efficiency Matrix has provided metric summaries for each VHA Surgery Program. Tables and figures illustrate summaries for differing timeframes for the entire surgery program, as well as by surgical specialty and by individual operating room. In addition, rolling 12-month metrics show easy comparison of individual surgery programs with other VISN surgery programs.

Table 3 and Figure 2 display metric rates by fiscal year. Since 
the introduction of the OR Efficiency Matrix, the following OR Efficiency metrics improved: median First-time Starts from $59.1 \%$ to $71.9 \%$, median Case Cancellations Rates from $14.2 \%$ to $7.6 \%$, OR Utilization from $60.8 \%$ to $63.2 \%$. Median OR Lag Time did not improve however low performers improved indicated by the limits of the Interquartile Range (IQR). Improvements in OR Lag Time allowed for the metric thresholds to be further tightened in FY16 Q1 resulting in a decrease in median OR Lag Time from $75.7 \%$ to $45.1 \%$.

OR Efficiency Matrix scores also showed marked improvement through the scoring bin modifications at FY16 Q1 (see Tables 4 and 5). The most significant change in scoring occurred in OR Lag Time due to the reset of the threshold times to much stricter standards. Scoring for First-time Starts and Case Cancellation saw similar drops in scoring due to the significant shifts in the scoring bins.
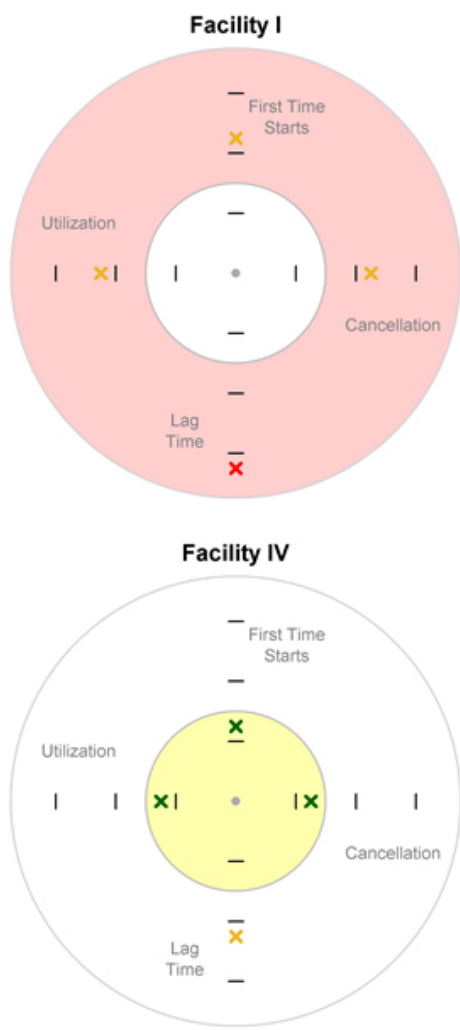
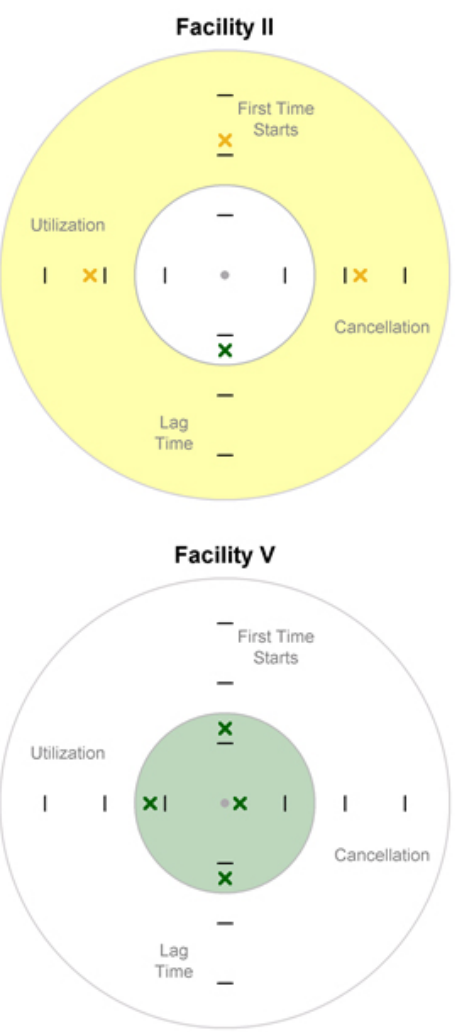
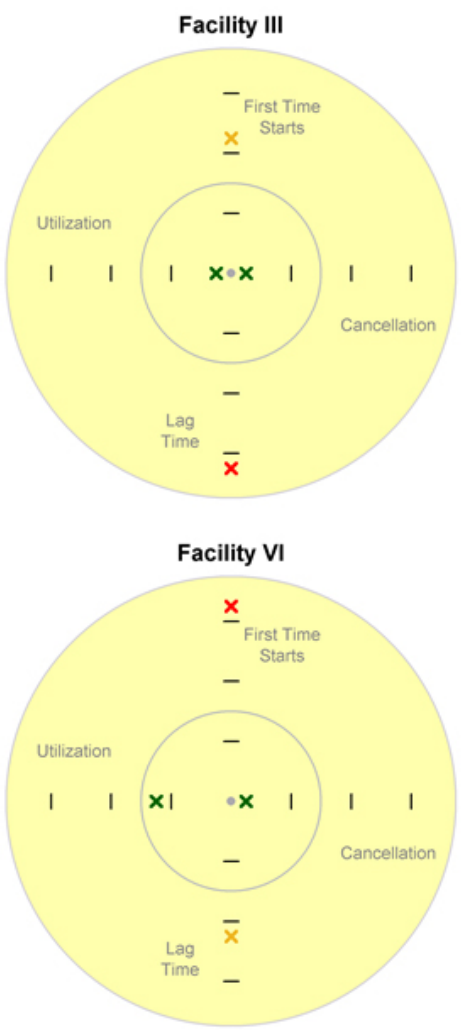

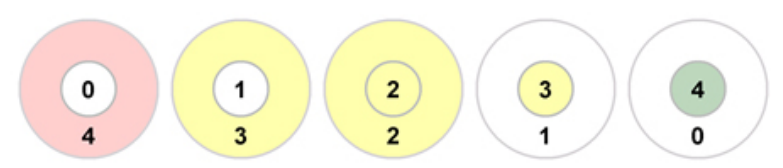

Figure 1. OR efficiency matrix - target plots

Table 3. OR efficiency matrix - rates by fiscal year

\begin{tabular}{llclclccc}
\hline \multirow{2}{*}{ Fiscal Year } & \multicolumn{2}{c}{ First-time Starts } & \multicolumn{2}{c}{ Case Cancellation } & \multicolumn{2}{c}{ OR Utilization } & \multicolumn{2}{c}{ OR Lag Time } \\
\cline { 2 - 9 } & Median & \multicolumn{1}{c}{ IQR } & Median & IQR & Median & IQR & Median & IQR \\
\hline FY13 & $59.1 \%$ & $(45.6 \%, 69.5 \%)$ & $14.2 \%$ & $(11.0 \%, 17.9 \%)$ & $60.8 \%$ & $(51.2 \%, 70.5 \%)$ & $75.0 \%$ & $(65.9 \%, 80.2 \%)$ \\
FY14 & $64.6 \%$ & $(53.2 \%, 74.8 \%)$ & $9.9 \%$ & $(7.8 \%, 12.4 \%)$ & $60.2 \%$ & $(46.1 \%, 69.4 \%)$ & $76.8 \%$ & $(65.5 \%, 81.9 \%)$ \\
FY15 & $68.9 \%$ & $(58.4 \%, 75.5 \%)$ & $9.1 \%$ & $(6.8 \%, 11.4 \%)$ & $61.9 \%$ & $(46.4 \%, 71.7 \%)$ & $75.7 \%$ & $(68.5 \%, 83.0 \%)$ \\
FY16 & $70.1 \%$ & $(61.5 \%, 78.7 \%)$ & $7.8 \%$ & $(5.9 \%, 10.2 \%)$ & $64.3 \%$ & $(50.6 \%, 73.2 \%)$ & $43.7 \%$ & $(31.2 \%, 58.4 \%)$ \\
FY17 & $71.9 \%$ & $(63.0 \%, 79.0 \%)$ & $7.6 \%$ & $(6.2 \%, 9.6 \%)$ & $63.2 \%$ & $(49.7 \%, 72.9 \%)$ & $45.1 \%$ & $(31.8 \%, 59.8 \%)$ \\
\hline
\end{tabular}


On Time FTS by Fiscal Year

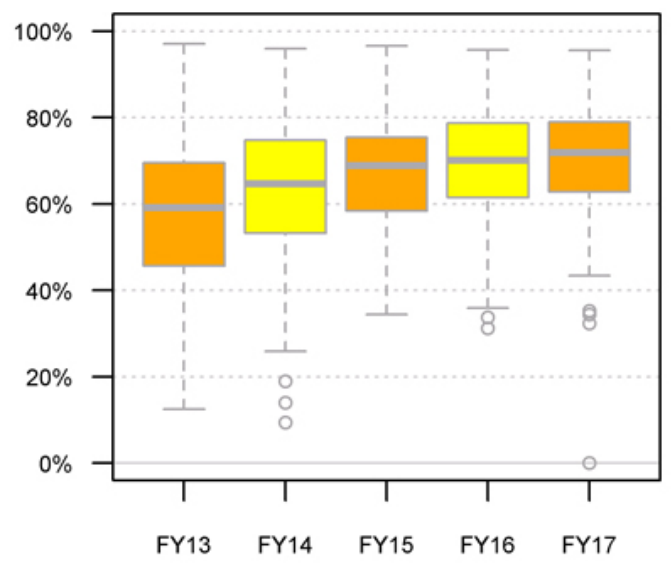

OR Utilization by Fiscal Year

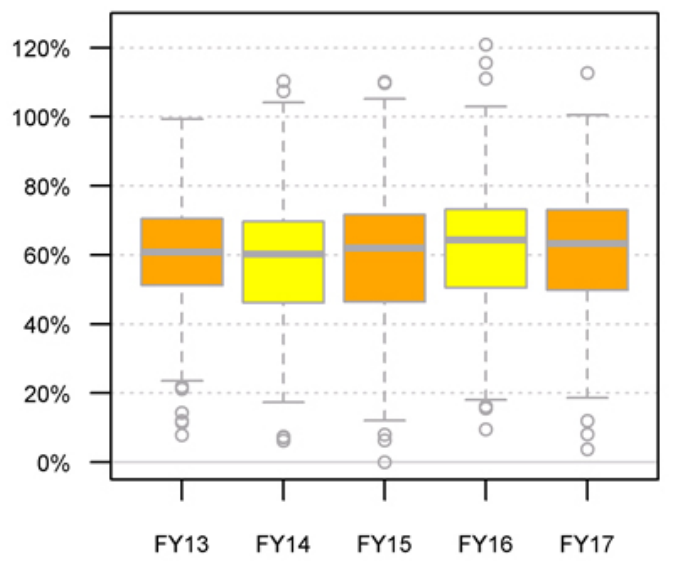

Cancellation Rate by Fiscal Year

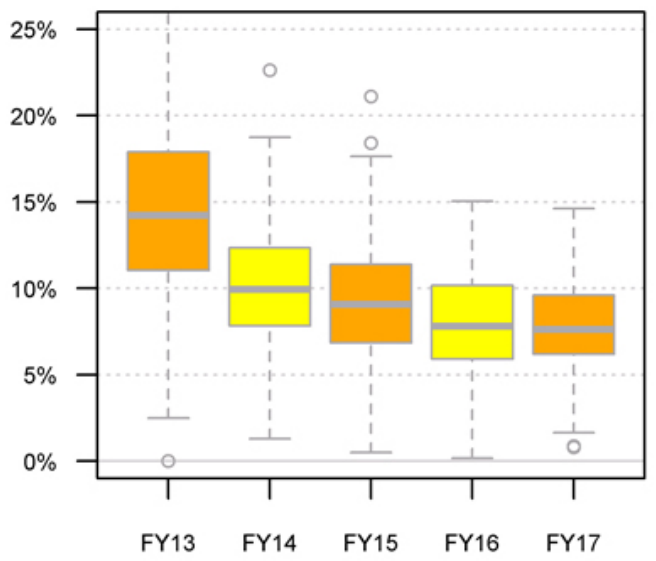

Lag Time by Fiscal Year

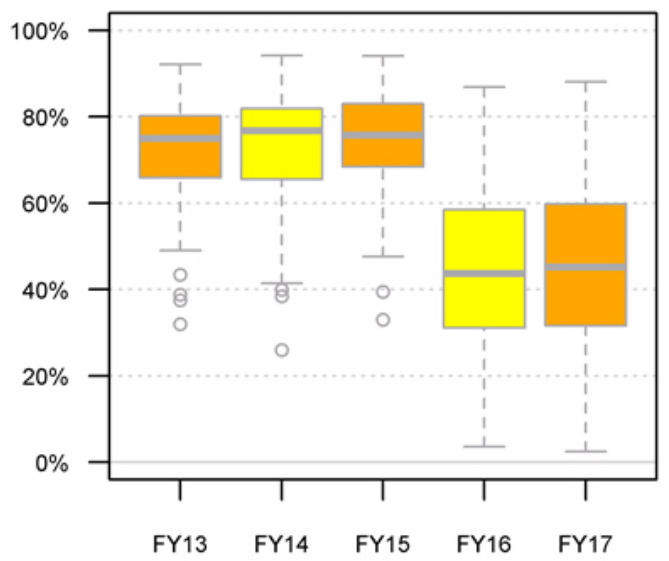

Figure 2. OR efficiency matrix - rates by fiscal year

Table 4. OR efficiency matrix metrics - mean scores by fiscal year

\begin{tabular}{llllll}
\hline Fiscal Year & First-time Starts & Cancellation & OR Utilization & OR Lag Time & Overall \\
\hline FY13 & 2.47 & 2.09 & 2.45 & 2.45 & 1.82 \\
FY14 & 2.74 & 2.94 & 2.45 & 2.54 & 2.40 \\
FY15 & 2.84 & 3.13 & 2.47 & 2.60 & 2.53 \\
FY16 & 2.55 & 2.81 & 2.60 & 1.96 & 2.03 \\
FY17 & 2.61 & 2.83 & 2.52 & 2.12 & 2.14 \\
\hline
\end{tabular}

Table 5. OR efficiency matrix - overall score distribution by fiscal year

\begin{tabular}{lllllll}
\hline Fiscal Year & $\mathbf{0}$ & $\mathbf{1}$ & $\mathbf{2}$ & $\mathbf{3}$ & $\mathbf{4}$ & Mean \\
\hline FY13 & 12 & 39 & 47 & 25 & 7 & 1.82 \\
FY14 & 4 & 24 & 36 & 53 & 16 & 2.40 \\
FY15 & 3 & 20 & 35 & 56 & 21 & 2.53 \\
FY16 & 8 & 31 & 50 & 39 & 6 & 2.03 \\
FY17 & 4 & 26 & 60 & 35 & 9 & 2.14 \\
\hline
\end{tabular}

\section{Discussion}

Improving OR efficiency can carry a substantial favorable impact on hospitals as the OR is often cited in the literature as an area of excessive cost. ${ }^{[12-15]}$ Estimates of up to $40 \%$ of a hospital's costs and $60 \%-70 \%$ of its revenue can be accountable to the OR. ${ }^{[16]}$ The literature indicates this is due to the intense human, equipment and infrastructure resource allocations required for the OR to function. ${ }^{[17]}$ Numerous measures of OR efficiency have been proposed, although 
no single one appears to represent the complexity of the OR environment. Improving OR efficiency is a challenging task, and multiple factors have been identified as contributing to inefficiencies; including patient factors, surgeon factors, system factors, and staffing factors. ${ }^{[6-8,18-21]}$

Multiple strategies have been reported for OR efficiency improvement. ${ }^{[22,23]}$ Due to the complexity of OR environment, the following interventions targeted isolated problems to improve OR efficiency: first case on-time start, turnover time, case volume, and OR utilization. ${ }^{[6,18-21,24]}$ Published studies report the impact of strategies to improve OR efficiency by one surgeon, one OR, or one institution. ${ }^{[25]}$ This is the first study to our knowledge that applies a single strategy across a large integrated health care system.

The specific metrics used in the VHA OR Efficiency Matrix were selected because they are commonly used in evaluating OR efficiency and impact access to care.$^{[4,12,13,26-30]}$ Factors influencing productivity and timeliness using the turnover time measure have been reported in numerous OR efficiency studies. ${ }^{[12,21,26,31-36]}$ As was noted in the Canadian Paediatric Surgical Wait Times Project, a lack of a standard methodology for measuring the outcomes in these studies limits the ability to benchmark externally. ${ }^{[4]}$ While there is a plethora of literature focusing on OR efficiency, to our knowledge this is the first study using a matrix of four metrics to measure, benchmark and report monitor OR efficiency that can benchmark improvements over time.

The NSO OR Efficiency Matrix provides a standardized method of evaluation within the VHA using four well known OR metrics. Our results showed that improvements occurred in each of the metrics which were sustained during the five years studied. Median first case on-time starts increased from $59.1 \%$ in FY2013 to $71.9 \%$ in FY2017, case cancellation decreased from $14.2 \%$ in FY2013 to $7.6 \%$ in FY2017, OR utilization increased from $60.8 \%$ in FY2013 to $63.2 \%$ in FY2017, and OR lag time threshold met rate increased from $43.7 \%$ in FY2016 to $45.1 \%$ in FY2017 (see Table 3). Therefore, benchmarking OR efficiency to a VHA standard and publishing comparative results drove improvement across the organization, most likely through local initiatives and shared VISN practices.

Benchmarking has been used elsewhere to successfully improve these key performance indicators of utilization, turnover time, and first-time starts. Van Veen-Berkx et al. showed that 4 of the 8 Dutch university medical centers in a national longitudinal study improved first-time starts with intervention. The successful outcome was attributed to a collaborative effort between medical centers which focused on sharing knowledge, discussing the data analysis results and identifying best practices. ${ }^{[30]}$ The Canadian Paediatric Wait Times Project included 15 centers from 8 Canadian provinces using common OR metrics including same-day cancellation rate, first-time starts, utilization and turnover time. Similarly, sharing knowledge across the participating hospitals was a critical component of measuring the overall OR performance. ${ }^{[4]}$ The NSO OR Efficiency Matrix is unique because it incorporates the effect of multiple metrics simultaneously over time and allows for comparison between VAMCs across a large integrated healthcare system.

Furthermore, establishing the OR Efficiency Matrix and a VHA benchmark allowed the NSO to identify low performers and collaborate with other VHA Program Offices to address improvement at these sites through a VHA Performance Improvement Initiative. Bidassie et al. reported the results of this initiative and the benefit of the OR Efficiency Matrix to drive improvement. ${ }^{[15,37]}$ Substantial and sustained improvements in OR efficiency were achieved using educational symposiums, face-to-face Rapid Process Improvement Workshops (RPIWs), and ongoing conference calls with VHA Surgery Program level Performance Improvement (PI) teams. The result of a two-year multi-phased performance improvement project was the elimination of the twenty low-performing VHA Surgery Programs and overall improvement in every metric. First-time starts improved by $24 \%$, lag time was reduced by $14 \%$, utilization improved by $8 \%$ and case cancellation rates were reduced by $5 \% .{ }^{[15]}$

There are limitations to our study. First, the 137 surgical programs are located in 18 VISNs, and the complexity of the surgical programs range from ambulatory to complex. It is possible that the impact of OR efficiency matrix on OR efficiency improvement may be associated with management practice of each VISN and the complexity of surgical programs. Second, the VHA surgical programs are not created based on marketing and demand. It might be difficult for rural programs to increase their OR utilization due to limited demand. Future studies will investigate the association of OR efficiency with the complexity of surgical programs and geographic location of hospitals.

\section{Conclusion}

This retrospective observational study demonstrates the overall impact of the OR Efficiency Matrix in improving OR efficiency across all VHA Surgery Programs for the period FY2013-2017. The regular and quarterly reporting of the OR Efficiency Matrix, comprised of metrics for First-time Starts, Case Cancellation Rates, OR Utilization, and OR Lag Time, was associated with continuous, ongoing, and sustained improvement in OR efficiency. Improvements in First-time Starts, Case Cancellation Rates, and OR Lag Time 
were most notable. These metrics are readily available and could be adopted by any health care system along with regular quarterly reporting to improve OR efficiency. Improved OR efficiency promotes OR capacity and optimal resource utilization thereby enhancing access to surgical care for Veterans.

\section{CONFlicts of INTEREST Disclosure}

The authors declare no conflicts of interest.

\section{REFERENCES}

[1] U.S. Department of Veterans Affairs, About Veterans Health Administration. 2018. Available from: https://www.va.gov/health/ aboutVHA.asp

[2] Personal communication, National Director of Surgery, VHA.

[3] Rothstein DH, Raval MV. Operating room efficiency. Seminars in Pediatric Surgery. 2018; 27: 79-85. PMid:29548356. https: //doi.org/10.1053/j.sempedsurg.2018.02.004

[4] Fixler T, Wright JG. Identification and use of operating room efficiency indicators; the problem of definition. Can J of Surg. 2013; 56(4): 224-226. PMid:23883490. https ://doi .org/10.1503/cj s. 020712

[5] Department of Veterans Affairs, VHA Handbook 1102.01, National Surgery Office. Available from: https://www.google. com/url?sa=t\&rct=j\&q=\&esrc= s\&source=web\&cd=1\&ved=2ahUKEw j $45 \mathrm{sCOponeAhWhTN8KHc}$ ZJAkwQFjAAegQICRAC\&url=https $\% 3 A \% 2 F \% 2 F w w w$. va.gov $\% 2 F$ vhapublications\%2FViewPublication.asp\%3Fpub_ID\%3D2 861\&usg=ADvVaw26Y6B6DyqZlsznrb290k83

[6] Panni MK, Shah SJ, Chavarro C, et al. Improving operating room first start efficiency and value of both checklist and a preoperative facilitator. Acta Anaesthesiol Scand. 2013; 57: 1118-1123. PMid:23898864. https://doi.org/10.1111/aas.12166

[7] Wright JG, Roche A, Khoury AE. Improving on-time surgical starts in an operating room. Can J Surg. 2010; 53: 167-170. PMid:20507788.

[8] Kodali BS, Kim D, Bleday R, et al. Successful strategies for the reduction of operating room turnover times in a tertiary care academic medical center. J Surg Res. 2014; 187: 403-411. PMid:24373960. https://doi.org/10.1016/j.jss.2013.11.1081

[9] Fezza M, Palermo GB. Simple solution for reducing first-procedure delays. AORN J. 2011; 93: 450-454. PMid:21459182. https: //doi.org/10.1016/j.aorn.2010.11.029

[10] Department of Veterans Affairs, VHA Directive 2010-018, Facility Infrastructure Requirements to Perform Standard, Intermediate, or Complex Surgical Procedures. Available from: https://www . google.com/url?sa=t\&rct=j\&q=\&esrc=s\&s ource=web\&cd=1\&ved=2ahUKEwif $60 \mathrm{fNrIneAhXonuAKHTIfAL}$ AQF jAAegQICRAC\&url=https $\% 3 \mathrm{~A} \% 2 \mathrm{~F} \% 2 \mathrm{Fwww}$. va. gov $\% 2 \mathrm{Fvhap}$ ublications \%2FViewPublication.asp\%3Fpub_ID\%3D222 7 \&usg=AOvVaw2drIdPxVJfN2WsxL6q87Ir

[11] Department of Veterans Affairs, VHA Directive 2011-037, Facility Infrastructure Requirements to Perform Invasive Procedures in an Ambulatory Surgery Center. Available from: https://www . google. com/url?sa=t\&rct=j\&q=\&esrc=s\&s ource=web\&cd=1\&ved=2ahUKEw jy6pGBrYneAhXEMd8KHf 2 YCJ kQFjAAegQICRAC\&url=https $\% 3 \mathrm{~A} \% 2 \mathrm{~F} \% 2 \mathrm{Fwww}$. va. gov $\% 2 \mathrm{Fvhap}$ ublications\%2FViewPublication. asp\%3Fpub_ID\%3D245 2\&usg=AOvVaw2QZJwwjD3If wbDZXuTpuTx

[12] Cima RR, Brown MJ, Hebl JR, et al. Use of lean and six sigma methodology to improve operating room efficiency in a high-volume tertiary-care academic medical center. J Am Coll Surg. 2011; 213: 89-92. PMid:21420879. https://doi.org/10.1016/j.jamcol lsurg. 2011.02.009

[13] Talati S, Gupta AK, Kumar A, et al. An analysis of time utilization and cancellations of scheduled cases in the main operation theater complex of a tertiary care teaching institute of North India. J of Postgraduate Med. 2015; 61(1): 3-8. PMid:25511210. https://doi.org/10.4103/0022-3859.147009

[14] Vassell P. Improving OR efficiency. AORN Journal. 2016; 104: 122129. PMid:27472972. https://doi .org/10.1016/j . aorn. 201 6.06 .006

[15] Bidassie B, Gunnar W, Starr L, et al. A Modified Collaborative Model to Improve Surgical Flow Health Care Processes in Veterans Affairs Medical Centers. International Journal of Healthcare. 2017; 3(2): 47-56. https://doi.org/10.5430/ijh.v3n2p47

[16] Rothstein DH, Raval MV. Operating room efficiency. Seminars in Pediatric Surgery. 2018; 27: 79-85. PMid:29548356. https: //doi.org/10.1053/j.sempedsurg. 2018.02.004

[17] Hariharan S, Chen D. Costs and utilization of operating rooms in a public hospital in Trinidad, West Indies. The Permanente Journal. 2015; 19(4): e128-e132. PMid:26828072.

[18] Sandbaek BE, Helgheim BI, Larsen OI, et al. Impact of changed management policies on operating room efficiency. BMC Health Serv Res. 2014; 14: 224. PMid:24885869. https://doi .org/10 .1186/1472-6963-14-224

[19] Friedman DM, Sokal SM, Chang Y, et al. Increasing operating room efficiency through parallel processing. Ann Surg. 2006; 243: 10-14. PMid:16371730. https://doi.org/10.1097/01.sla.0000193 $600.97748 . \mathrm{b} 1$

[20] Dexter F, Epstein RH. Operating room efficiency and scheduling. Curr Opin Anaesthesiol. 2005; 18: 195-198. PMid:16534338. https://doi.org/10.1097/01.aco.0000162840.02087.15

[21] Harders M, Malangoni MA, Weight $S$, et al. Improving operating room efficiency through process redesign. Surgery. 2006; 140: 509514. PMid:17011897. https ://doi.org/10.1016/j.surg. 200 6.06 .018

[22] Tsai MH, Breidenstein MW, Flanagan TF, et al. Applying performance frontiers in operating room management: A tutorial using data from an academic medical center. A A Pract. 2018; Aug 29. https://doi.org/10.1213/XAA.0000000000000873

[23] Tagge EP, Thirumoorthi AS, Lenart J, et al. Improving operating room efficiency in academic children's hospital using Lean Six Sigma methodology. J Pediatr Surg. 2017; 52(6): 1040-1044. PMid:28389078. https://doi.org/10.1016/j.jpedsurg. 201 7.03 .035

[24] Kimbrough CW, McMasters KM, Canary J, et al. Improved operating room efficiency via constraint management: Experience of a tertiary-care academic medical center. J Am Coll Surg. 2015; 221(1): 154-62. PMid:26095565. https : //doi.org/10.1016/j.jamcol lsurg. 2015.02.032 
[25] Fong AJ, Smith M, Langerman A. Efficiency improvement in the operating room. J Surg Res. 2016; 204(2): 371-383. PMid:27565073. https://doi.org/10.1016/j.jss.2016.04.054

[26] Scalea TM, Carco D, Reece M, et al. Effect of a Novel Financial Incentive Program on Operating Room Efficiency. JAMA Surgery. 2014; 149(9): 920-924. PMid:25103471. https ://doi.org/10.1 001/jamasurg. 2014.1233

[27] Bender JS, Nicolescu TO, Hollingsworth SB, et al. Improving operating room efficiency via an interprofessional approach. The American Journal of Surgery. 2015; 209: 447-450. PMid:25770394. https://doi.org/10.1016/j.amjsurg. 2014.12.007

[28] Heslin MJ, Doster BE, Daily SL, et al. Durable Improvements in Efficiency, Safety, and Satisfaction in the Operating Room. Am Coll Surg. 2008; 206: 1083-1090. PMid:18471761. https ://doi.org/ 10.1016/j.jamcollsurg. 2008.02.006

[29] Clark A, Dackiw AP, White WD, et al. Early endocrine attending surgeon presence increases operating room efficiency. Journal of Surgical Research. 2016; 205: 272-278. PMid:27664872. https://doi.org/10.1016/j.jss.2016.06.093

[30] Van Veen-Berkx E, Elkhuizen SG, Kalkman CJ, et al. Successful interventions to reduce first-case tardiness in Dutch university medical centers: Results of a nationwide operating room benchmark study. The American Journal of Surgery. 2014; 207: 949-959. PMid:24534558. https ://doi.org/10.1016/j.amjsurg. 2013 .09 .025

[31] Forse RA, Bramble JD, McQuillan R. Team training can improve operating room performance. Surgery. 2011; 150(4): 771-778.
PMid:22000190. https://doi.org/10.1016/j.surg.2011.07 .076

[32] Divatia JV, Ranganathan P. Can we improve operating room efficiency? J Postgrad Med. 2015; 61(1): 1-2. PMid:25511209. https://doi.org/10.4103/0022-3859.147000

[33] Collar RM, Shuman AG, Feiner S, et al. Lean management in academic surgery. J Am Coll Surg. 2012; 214: 928-936. PMid:22626546. https://doi.org/10.1016/j.jamcollsurg.2012.03.002

[34] Friedman DM, Sokal SM, Chang Y, et al. Increasing operating room efficiency through parallel processing. Ann Surg. 2006; 243(1): 10-14. PMid:16371730. https://doi.org/10.1097/01.sla.0 $000193600.97748 . \mathrm{b} 1$

[35] Mizumoto R, Cristaudo AT, Hendahewa R. A surgeon-led model to improve operating theatre change-over time and overall efficiency: A randomized controlled trial. International Journal of Surgery. 2016; 30: 83-89. PMid:27109202. https ://doi.org/10.1016/j.ijsu .2016 .04 .033

[36] Padegimas EM, Hendy BA, Lawrence C, et al. An analysis of surgical and nonsurgical operating room times in high-volume shoulder arthroplasty. Journal of Shoulder and Elbow Surgery. 2017; 30(6): 1058-1063. PMid:28131689. https ://doi.org/10.1016/j.jse. 2016.11.040

[37] Bidassie B, Gunnar W, Starr L, et al. Data Driven Process to Improve VA Surgical Flow. Int J Health Care Quality Assurance. 2018; 31(4): 1-13. PMid:29790447. https ://doi.org/10.1108/IJHC QA-03-2017-0053 